\title{
A burden of illness study for neuropathic pain in Europe
}

This article was published in the following Dove Press journal:

Clinico Economics and Outcomes Research

27 April 2016

Number of times this article has been viewed

\author{
Hiltrud Liedgens' \\ Marko Obradovic' \\ Jonathan De Courcy ${ }^{2}$ \\ Timothy Holbrook ${ }^{2}$ \\ Rafal Jakubanis ${ }^{2}$ \\ 'Grunenthal, Aachen, Germany; \\ ${ }^{2}$ Adelphi Real World, Bollington, \\ Cheshire, UK
}

Correspondence: Hiltrud Liedgens Grunenthal, Zieglerstraße 6, 52078 Aachen, Germany

Tel +4924I 5692679

Email Hiltrud.Liedgens@grunenthal.com
Purpose: Neuropathic pain (NP) is often severe and represents a major humanistic and economic burden. This study aimed at providing insight on this burden across France, Germany, Italy, Spain, and the UK, considering direct and indirect costs, productivity loss, and humanistic impact on patients and their families.

Methods: Physician questionnaires provided data on patients presenting with NP covering demographics, sick leave and retirement, number of consultations, drug treatments, and surgical procedures. Patients provided further demographic and disease-related data and completed the Work Productivity and Activity Impairment (WPAI), the EuroQol 5-Dimension (EQ-5D), and the Brief Pain Inventory (BPI) questionnaires. All health-related direct unitary costs were collected from relevant country-specific sources and adjusted to 2012 prices $(€)$ where necessary. A subgroup analysis of costs based on diabetic peripheral neuropathy $(n=894)$, fibromyalgia ( $\mathrm{n}=300)$, and low back pain $(\mathrm{n}=963)$ was performed.

Findings: About 413 physicians completed a total of 3,956 patient records forms. Total annual direct health-care costs per patient ranged from $€ 1,939$ (Italy) to $€ 3,131$ (Spain). Annual professional caregiver costs ranged from $€ 393$ (France) to $€ 1,242$ (UK), but this only represented a small proportion of total care because much care is provided by family or friends. Sick leave costs ranged from $€ 5,492$ (UK) to $€ 7,098$ (France), with $10 \%-32 \%$ patients prevented from working at some point by NP. Total cost (including direct and indirect costs) of NP per patient was $€ 10,313$ in France (69\% of the total cost), €14,446 in Germany (78\%), €9,305 in Italy (69\%), $€ 10,597$ in Spain (67\%), and €9,685 in the UK (57\%). Indirect costs (ie, sick leave) constituted the majority of costs in all five countries: $€ 7,098$ in France, $€ 11,232$ in Germany, $€ 6,382$ in Italy, $€ 7,066$ in Spain, and $€ 5,492$ in the UK. In the subgroup analysis, total annual direct costs per patient were highest for neuropathic back pain and radiculopathy, and lowest for fibromyalgia. Mean WPAI score range was 34.4-56.1; BPI interference was 4.1-4.8; and EQ-5D was $0.57-0.74$. The results suggest that a significant proportion of the patient's work time in the previous week was affected by NP, and these are relatively high compared with other diseases such as diabetes, respiratory conditions, and arthritis.

Implications: Despite differences in practice between countries, these findings suggest a high opportunity cost for society in terms of lost work and productivity due to NP. The wider costs appear significantly higher to patients, carers/families, and society as a whole than to the health system alone.

Keywords: neuropathic pain, burden of illness, chronic lower back pain, productivity

\section{Introduction}

Chronic pain is a distinct and well-recognized condition experienced by around $25 \%$ of the European adult population. ${ }^{1}$ While the majority of chronic pain is nociceptive 
in origin, ie, arising from actual or threatened damage to nonneural tissue, ${ }^{2}$ a proportion of chronic pain arises as "a direct consequence of a lesion or disease affecting the somatosensory system". ${ }^{3}$ This is termed neuropathic pain (NP). Examples of conditions where pain is of a purely neuropathic origin include multiple sclerosis, diabetic neuropathy, and postherpetic neuralgia (PHN). Chronic pain often has both nociceptive and neuropathic components, with back pain being the most common example. ${ }^{4}$ Symptoms indicative of NP have been reported by around one-third of patients with back pain. ${ }^{5,6}$ The proportion of patients with pain classified as "positive neuropathic" can differ substantially between pain grades, with NP usually associated with higher pain severity. ${ }^{6}$ Analysis of US health insurance claims data suggests that back and neck pain with neuropathic involvement is probably the most frequent neuropathic disorder. ${ }^{7}$

NP is estimated to affect $7 \%-8 \%$ of the population in Europe, ${ }^{8,9}$ yet some estimates have suggested that as many as $20 \%$ of adults in Europe may be affected ${ }^{10}$ and that close to half of those are affected on a daily basis.

NP appears to be more difficult to treat than many other types of chronic pain. ${ }^{11,12}$ Strong opioids are effective for nociceptive pain, but less effective in NP or in pain conditions with a NP component, ${ }^{12}$ often requiring higher doses and therefore resulting in tolerability issues. ${ }^{13,14}$ Combination therapy with anticonvulsants such as pregabalin or gabapentin is used, ${ }^{12}$ but this also increases the risk of adverse events. ${ }^{15}$ In terms of clinical guidance, the European Federation of Neurological Societies guidelines on NP recommend pregabalin, gabapentin, duloxetine, tricyclic antidepressants, and venlafaxine for first-line treatment, with opioids and tramadol reserved for second line. ${ }^{16}$

The humanistic and economic impacts are also considerable. The results of a European cross-sectional survey ${ }^{17}$ have demonstrated the major impact of chronic NP on patients' general activity, mood, walking, work, relations with others, sleep, and enjoyment of life, with $43 \%$ of these patients also reporting disruption to employment status. This also applies to chronic pain overall, with another European survey reporting that owing to chronic pain, $19 \%$ sufferers lost their job, $16 \%$ changed job responsibilities, and $13 \%$ had to change jobs entirely. ${ }^{18}$

Overall, chronic pain with a neuropathic component is more frequently associated with severe pain, ${ }^{4,6}$ a greater number and greater severity of comorbidities, ${ }^{4}$ a reduced quality of life, ${ }^{11,19}$ and overall higher health-care costs, ${ }^{6,20}$ compared with non-NP.

Since the current health technology assessment frameworks adopted by developed economies almost exclusively consider only direct costs (upon which conventional cost effectiveness modeling is based), only a small part of the overall impact of chronic pain and the overall cost burden to society, of which NP is a major driver, will be captured. It is therefore important to acknowledge that the real burden of NP is underrecognized.

To help assess this wider burden, this study aimed at providing a holistic insight in to the costs associated with NP across France, Germany, Italy, Spain, and the UK. The study was designed to consider the impact of the condition on wider issues such as productivity losses and caregiver costs as well as the humanistic impact on patients and their families, thus providing a more comprehensive estimation of the real opportunity costs for society associated with optimal management of the condition.

\section{Methods \\ Primary data source}

Data were drawn from the Adelphi Neuropathic Pain Disease Specific Programme (DSP $\left.{ }^{\circledR}\right)$, a survey of real-world clinical practice conducted in Germany, France, Italy, Spain, and the UK in 2012. ${ }^{21}$ The Neuropathic Pain DSP was run in accordance with the European Pharmaceutical Market Research Association (EphMRA) guidelines. EphMRA guidelines define the DSP as a market research survey, designed only to gain insight into real world clinical practice with no set

Table I Composition of data from the disease specific program database

\begin{tabular}{|c|c|c|c|c|c|c|c|c|}
\hline \multirow[t]{2}{*}{ Country } & \multicolumn{8}{|l|}{$\mathbf{N}$} \\
\hline & $\mathbf{P C P}$ & Neurologist & Anesthetist & Diabetologist & $\begin{array}{l}\text { Orthopedic } \\
\text { surgeon }\end{array}$ & Rheumatologist & PRF & PSC \\
\hline France & 24 & 19 & 11 & 11 & 8 & 11 & 807 & 602 \\
\hline Germany & 25 & 15 & 18 & 10 & 7 & 9 & 802 & 693 \\
\hline Italy & 24 & 17 & 17 & 10 & 8 & 8 & 792 & 225 \\
\hline Spain & 24 & 16 & 18 & 10 & 8 & 8 & 826 & 577 \\
\hline UK & 24 & 16 & 15 & 10 & 3 & 9 & 729 & 437 \\
\hline Total & $|2|$ & 83 & 79 & 51 & 34 & 45 & 3,956 & 2,534 \\
\hline
\end{tabular}

Abbreviations: PCP, primary care physicians; PRF, patient record form; PSC, patient self-completion questionnaire. 
protocol or hypothesis and as such is deemed not to require ethical or review board approval. Patients provided informed consent for use of their anonymized and aggregated data for research and publication in scientific journals. This was achieved by means of a check box on the front page of the patient completed survey. Data were collected such that the subjects cannot be identified directly, or linked to the participants; and as such are fully in line with HIPAA, the US Health Insurance Portability and Accountability Act 1996 (HIPAA; http://www.hhs.gov/ocr/privacy/), HITECH and similar European guidelines. The DSP is a cross-sectional patient record-based survey of specialists (neurologists, anesthetists, pain clinic physicians, diabetologists, orthopedic surgeons, and rheumatologists) and primary care physicians (PCPs) and their patients with NP. Table 1 lists the distribution of physicians by specialty across countries. Physicians were identified from public lists of health-care professionals, with few restrictions other than they manage, and make treatment decisions for, NP patients. PCPs were required to see a minimum of $12 \mathrm{NP}$ patients a month, and the specialists a minimum of 10 . This was to ensure that the minimum sample of patients would be collected in a reasonable time frame.

Physicians were asked to complete a comprehensive patient record form (PRF) for the next eight patients who presented with NP, or the next ten patients for specialists. This included quantitative information on indirect burden, such as time of current sick leave, and proportion of people that had retired from work due to their NP condition, along with their mean age. These data were used to calculate two indirect costs: current sick leave and early retirement. In addition to this, physicians also provided information on direct burden including number of consultations, prescribed drug treatment, and surgical procedures. The collection of sick leave duration was not restricted to a set time period. These data were censored at 52 weeks to allow annualization of costs across countries. Patients provided further demographic and disease-related data and also completed three validated Patient Reported Outcomes questionnaires: the Work Productivity and Activity Impairment Questionnaire (WPAI) to assess work and activities' impairment, the EuroQol 5 Dimension (EQ-5D, 3L) to assess quality of life, and the Brief Pain Inventory interference questionnaire (BPI) to assess the level of pain from their condition. The total numbers of patients included is also listed in Table 1, together with the number of patients who completed a self-completion questionnaire. The Patient Self-Completion questionnaire was voluntary, and so not all patients participated in this aspect of the survey.
Physicians and patients provided anonymized data in accordance with Health Insurance Portability and Accountability Act 1996 and the European Pharmaceutical Market Research Association code of conduct for international health-care market research.

Patients provided informed consent for the deidentified and aggregated reporting of research findings. All data were fully deidentified and aggregated prior to analysis. Full details of the methodology have been published previously. ${ }^{21}$

\section{Data analysis}

This analysis set out to identify the cost burden of NP from a societal perspective, and extracted data on direct health costs (prescribed drugs, health care professional visits, and surgical and nonsurgical procedures for the management of the disease); direct nonhealth-care costs such as provision of (paid) social care/support; and indirect costs such as work and productivity loss.

The individual patient cost profiles were developed using a bottom-up approach. This was to enable insight into the primary drivers of the overall cost among NP patients (within the sample used).

\section{Direct costs}

The direct health-related costs were taken as the sum of consultations, prescribed drugs, and surgical and nonsurgical procedures undertaken for the management of NP. Also included were alternative therapies used by patients to manage their pain. For alternative therapies, an assumption of classes for 6 months duration (for therapies such as yoga, swimming, and relaxation techniques) or costs for six single sessions (massages, acupuncture, chiropractice) were computed for the extrapolation to annual costs.

Direct nonhealth-related costs include caregiving costs (professional caregivers only). The number of hours of informal care received by the participating patients was also assessed. Informal care was defined as care given by a neighbor, family member, spouse, volunteer, or a friend. Potential indirect costs associated with this mode of care were omitted as it was not confirmed if the caregiver received state benefit/ subsidy or if they lost working hours due to care provided. Therefore, this was not included in the final costing, but was used to provide insight into the wider societal impact.

\section{Indirect costs}

Indirect costs included salary and time adjustment of patients on sick leave. Since only the duration of any current period of sick leave was collected, cost of time off work due to NP was 
calculated based on the proportion of patients on sick leave and average annual salary. Indirect costs associated with NP were calculated using the human capital approach, with only sick leave at the point of consultation accounted for. The humancapital method takes the patient's perspective and counts any hour not worked as an hour lost. By contrast, an alternative, the friction-cost method takes the employer's perspective, and only counts as lost those hours not worked until another employee takes over the patient's work. These methods can produce widely different results, with the human capital approach taking a more holistic societal view, and resulting in typically higher costs. The friction-cost method assumes that employees are easy to replace (both in terms of skills and the ability to immediately replace a sick employee), which may not always be the case, and does not encompass the patient perspective, which is an important factor in analysis from a societal aspect. No costs related to early retirement or reduction of working hours were included, but evidence on both was provided.

Impairment while at work was assessed through the WPAI score. The WPAI was created as a patient-reported quantitative assessment of the amount of absenteeism, presenteeism, and daily activity impairment attributable to a specific health problem. Scores range from 0 to 100 , with a higher score indicating a greater level of impairment (or lesser ability to perform every day functions including work).

\section{Collection and application of unit costs}

All health-related direct unitary costs were collected from relevant and updated country-specific sources and adjusted to 2012 prices where necessary using general inflation rates. Generic prices were used for drug costs and were collected for the most prevalent drugs in each country (about $90 \%$ of the total drugs); a median price was imputed for the remaining minority. (In cases where drug costs were not available, a median value for all drug costs held was imputed.)

Estimates of resource use costs were taken from a wide variety of publicly available sources wherever these were available. All costs were collected in $€$, other than for the UK. For ease of comparison, UK sterling was converted into $€$.

Costs in France were taken from www.ameli.fr, with Diagnoses Related Group (DRG) costs taken from www. legifrance.gouv. .r. $^{22}$

In Germany, many costs (consultations, procedures, and alternative therapies) were drawn from tariffs laid down by the National Association of Physicians. ${ }^{23}$ However, the cost of some alternative treatments such as yoga, swimming, and Pilates were estimated from a health insurance tariff (it should be noted that only two such courses per year are allowed). ${ }^{24}$ Drug prices were estimated using information from the Lauer-Fischer database. ${ }^{25}$

In Italy, costs for surgical and nonsurgical procedures, plus those for alternative therapies, were estimated from national tariffs for the remuneration of health benefits. ${ }^{26}$ Drug prices were also taken from government sources. ${ }^{27}$ The cost of general practitioner (GP) consultations was taken from national tariffs ${ }^{28}$ and the cost of other (specialist or nurse) consultations from a small hospital-based study. ${ }^{29}$

For Spain, most costs were collected from the Department of Health in Spain (Ministerio de Sanidad, Servicios Sociales e Igualdad), with costs for surgical and nonsurgical procedures taken from Spanish DRG codes, including hospitalization costs based on data about average stay. ${ }^{30}$

In the UK, costs for surgical and nonsurgical procedures were contained within DRG codes and Healthcare Resource Groups, which include the unit costs of the procedures and the hospitalization costs based on average stays of each procedure. Primary care costs were taken from the PSSRU ${ }^{31}$ database, and drug prices taken from MIMS. ${ }^{32}$

The proportion of patients on sick leave at any one time was used as the basis for calculation of the cost of time off work due to NP rather than the duration of sick leave since sick leave can be ongoing, which would result in an underestimate of the true cost. The mean wage rates used to estimate the burden of time off work were taken from Eurostat, ${ }^{33}$ which provides mean annual incomes for all EU member states.

\section{Patient quality of life}

The BPI questionnaire measures how much the pain has interfered with seven daily activities, including general activity, walking, work, mood, enjoyment of life, relations with others, and sleep, with 0 being no interference and 10 being complete interference.

The EQ-5D tool is well validated and is one of the most commonly used questionnaires for calculating a utility score. ${ }^{34-36}$ It is composed of five dimensions (mobility, selfcare, usual activities, pain or discomfort, and anxiety or depression), each with three levels of patient performance (no problems, some problems, or extreme problems/unable to). A total of 245 health states can be created, with 0 representing death and 1 perfect health.

\section{Subgroup analyses}

In addition, subgroup analyses were conducted to estimate the cost implications associated with some of the most 
Table 2 EU5 physician-recorded patient demographics

\begin{tabular}{|c|c|c|c|c|c|c|}
\hline Patient characteristics & $\begin{array}{l}\text { Total } \\
(n=3,956)\end{array}$ & $\begin{array}{l}\text { France } \\
(n=807)\end{array}$ & $\begin{array}{l}\text { Germany } \\
(n=802)\end{array}$ & $\begin{array}{l}\text { Italy } \\
(n=792)\end{array}$ & $\begin{array}{l}\text { Spain } \\
(n=826)\end{array}$ & $\begin{array}{l}\text { UK } \\
(n=729)\end{array}$ \\
\hline PSC completion rate & & $73 \%$ & $76 \%$ & $28 \%$ & $60 \%$ & $61 \%$ \\
\hline Age (mean) & 57.9 & 56.8 & 58.3 & 60.7 & 57.3 & 56.2 \\
\hline \multicolumn{7}{|l|}{ Sex } \\
\hline Male & $46.5 \%$ & $49.9 \%$ & $47.8 \%$ & $45.5 \%$ & $44.3 \%$ & $44.9 \%$ \\
\hline Female & $53.5 \%$ & $50.1 \%$ & $52.2 \%$ & $54.4 \%$ & $55.7 \%$ & $55.1 \%$ \\
\hline NS & $0.0 \%$ & $0.0 \%$ & $0.0 \%$ & $0.1 \%$ & $0.0 \%$ & $0.0 \%$ \\
\hline BMI score (mean) & 26.5 & 26.0 & 27.2 & 25.7 & 26.1 & 27.7 \\
\hline \multicolumn{7}{|c|}{ Concomitant conditions (current) } \\
\hline Hypertension & $41.0 \%$ & $40.6 \%$ & $49.1 \%$ & $44.9 \%$ & $32.8 \%$ & $37.4 \%$ \\
\hline Diabetes & $29.9 \%$ & $32.2 \%$ & $32.3 \%$ & $31.7 \%$ & $27.8 \%$ & $25.1 \%$ \\
\hline High cholesterol & $23.6 \%$ & $21.9 \%$ & $25.2 \%$ & $23.1 \%$ & $27.5 \%$ & $20.0 \%$ \\
\hline Depression & $18.9 \%$ & $17.7 \%$ & $21.1 \%$ & $21.6 \%$ & $17.1 \%$ & $17.0 \%$ \\
\hline Anxiety & $17.9 \%$ & $26.6 \%$ & $7.0 \%$ & $23.0 \%$ & $19.0 \%$ & $13.6 \%$ \\
\hline Sleep disorders & $14.5 \%$ & $20.2 \%$ & $20.8 \%$ & $12.8 \%$ & $10.8 \%$ & $7.5 \%$ \\
\hline Other cardiovascular conditions & $8.9 \%$ & $\mathrm{I} 1.4 \%$ & $10.3 \%$ & $8.0 \%$ & $6.7 \%$ & $8.2 \%$ \\
\hline Arthritis & $8.7 \%$ & $5.1 \%$ & $11.3 \%$ & $5.4 \%$ & $5.9 \%$ & $16.6 \%$ \\
\hline Respiratory disorder & $5.5 \%$ & $3.5 \%$ & $7.4 \%$ & $5.6 \%$ & $4.8 \%$ & $6.2 \%$ \\
\hline Migraine & $4.6 \%$ & $3.3 \%$ & $4.1 \%$ & $4.5 \%$ & $6.1 \%$ & $5.1 \%$ \\
\hline Cancer & $3.6 \%$ & $4.6 \%$ & $3.5 \%$ & $4.4 \%$ & $3.5 \%$ & $1.8 \%$ \\
\hline Nausea & $1.7 \%$ & $0.9 \%$ & $2.4 \%$ & $1.5 \%$ & $1.1 \%$ & $2.7 \%$ \\
\hline Panic disorders & $1.7 \%$ & $0.7 \%$ & $3.0 \%$ & $2.8 \%$ & $0.1 \%$ & $1.8 \%$ \\
\hline Dementia & $1.4 \%$ & $0.6 \%$ & $2.1 \%$ & $0.9 \%$ & $1.7 \%$ & $1.5 \%$ \\
\hline
\end{tabular}

Abbreviations: PSC, patient self-completion questionnaire; NS, nonspecified; BMI, body mass index.

prevalent indications from within the collated sample. We include in this subgroup analysis only those patients who have one of the seven most commonly stated causes of $\mathrm{NP}$ in the survey; diabetic peripheral neuropathy $(\mathrm{n}=294)$, radiculopathy $(n=157)$, fibromyalgia $(n=65)$, postsurgical neuropathy ( $\mathrm{n}=65)$, chronic idiopathic polyneuropathy $(\mathrm{n}=64), \operatorname{PHN}(\mathrm{n}=57)$, and carpal tunnel syndrome $(\mathrm{n}=35)$. In addition, patients with neuropathic back pain $(\mathrm{n}=126)$ were also analyzed. To facilitate a like for like comparison, patients with more than one of these conditions were excluded from the analysis, though patients who had other conditions in addition to one of those listed above were included. Analysis was based only on direct health sector costs: all nonhealth sector and indirect costs were excluded from this analysis owing to sample size.

The costs for the subgroup analysis were computed using a weighted average of the five countries' resource use costs.

Differences in burden between different patient subgroups (ie, different peripheral diseases) was tested using

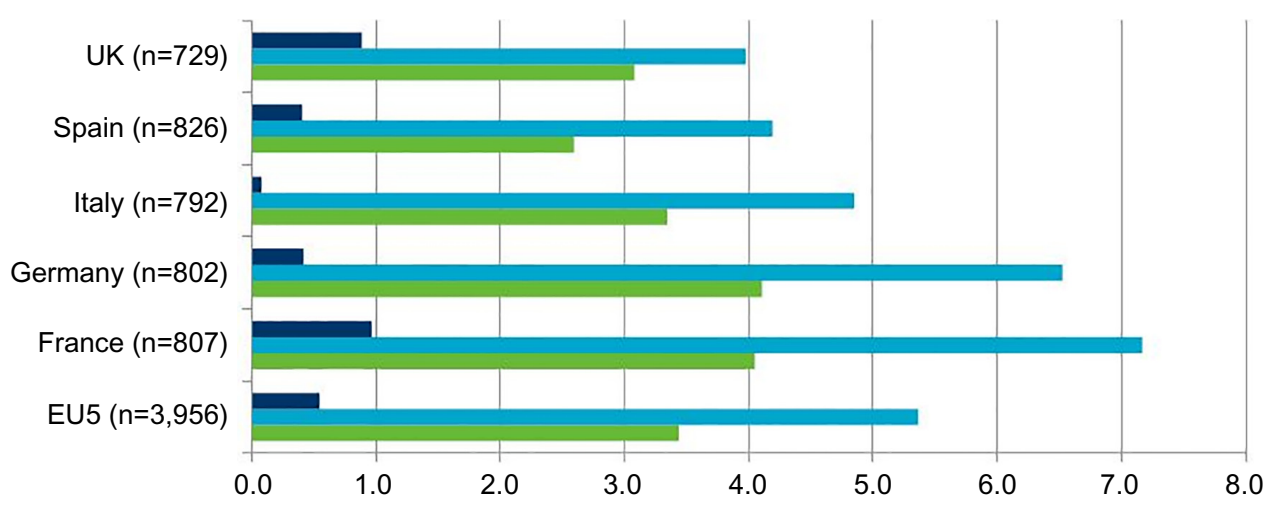

nurses consultations Specialists consultations PCP/GP consultations

Figure I Mean number of annual consultations per patient in each country and as average across all five countries (EU5), 20 I2.

Abbreviations: PCP, primary care physicians; GP, general practitioner. 
Table 3 Physician-recorded diagnoses of neuropathic pain ( $>1 \%)$

\begin{tabular}{|c|c|c|c|c|c|c|}
\hline Pain-related patient characteristics & $\begin{array}{l}\text { Total } \\
(n=3,956)\end{array}$ & $\begin{array}{l}\text { France } \\
(n=807)\end{array}$ & $\begin{array}{l}\text { Germany } \\
(n=802)\end{array}$ & $\begin{array}{l}\text { Italy } \\
(n=792)\end{array}$ & $\begin{array}{l}\text { Spain } \\
(n=826)\end{array}$ & $\begin{array}{l}\text { UK } \\
(n=729)\end{array}$ \\
\hline \multicolumn{7}{|l|}{ BPI score (average pain) } \\
\hline Mean & 4.4 & 4.3 & 3.8 & 4.3 & 4.8 & 5.0 \\
\hline \multicolumn{7}{|l|}{ Neuropathic pain diagnosis } \\
\hline \multicolumn{7}{|l|}{ Central } \\
\hline Trigeminal neuralgia & $4.1 \%$ & $2.7 \%$ & $4.4 \%$ & $3.7 \%$ & $5.6 \%$ & $4.1 \%$ \\
\hline Multiple sclerosis & $2.5 \%$ & $2.7 \%$ & $1.7 \%$ & $1.8 \%$ & $1.6 \%$ & $4.8 \%$ \\
\hline Postsurgical neuropathy & $2.4 \%$ & $2.7 \%$ & $2.6 \%$ & $2.1 \%$ & $1.7 \%$ & $3.0 \%$ \\
\hline Central poststroke pain & $2.2 \%$ & $2.4 \%$ & $2.6 \%$ & $1.9 \%$ & $2.1 \%$ & $2.3 \%$ \\
\hline Posttraumatic neuropathy & $1.6 \%$ & $1.5 \%$ & $2.0 \%$ & $2.7 \%$ & $1.0 \%$ & $1.1 \%$ \\
\hline Postsurgery trauma & $1.5 \%$ & $1.5 \%$ & $0.6 \%$ & $2.1 \%$ & $0.8 \%$ & $2.7 \%$ \\
\hline Spinal cord injury & $1.5 \%$ & $0.6 \%$ & $0.4 \%$ & $3.3 \%$ & $2.2 \%$ & $1.1 \%$ \\
\hline \multicolumn{7}{|l|}{ Peripheral } \\
\hline Diabetic peripheral neuropathy & $22.6 \%$ & $25.7 \%$ & $27.2 \%$ & $23.4 \%$ & $17.1 \%$ & $19.6 \%$ \\
\hline Spinal nerve root pain (radiculopathy) & $18.5 \%$ & $13.5 \%$ & $20.0 \%$ & $16.5 \%$ & $21.2 \%$ & $21.5 \%$ \\
\hline Fibromyalgia & $7.6 \%$ & $4.0 \%$ & $7.7 \%$ & $10.4 \%$ & $6.3 \%$ & $9.9 \%$ \\
\hline Postherpetic neuralgia & $7.4 \%$ & $4.5 \%$ & $8.1 \%$ & $7.6 \%$ & $9.2 \%$ & $7.8 \%$ \\
\hline Postsurgical neuropathy & $7.2 \%$ & $10.8 \%$ & $7.4 \%$ & $5.2 \%$ & $6.9 \%$ & $5.6 \%$ \\
\hline Carpal tunnel & $6.1 \%$ & $3.7 \%$ & $3.9 \%$ & $9.2 \%$ & $8.6 \%$ & $5.1 \%$ \\
\hline Chronic idiopathic polyneuropathy & $4.6 \%$ & $5.6 \%$ & $7.5 \%$ & $6.1 \%$ & $1.5 \%$ & $2.5 \%$ \\
\hline Posttraumatic neuropathy & $3.2 \%$ & $4.7 \%$ & $2.1 \%$ & $4.0 \%$ & $3.3 \%$ & $1.8 \%$ \\
\hline Small fiber neuropathy & $3.2 \%$ & $1.1 \%$ & $4.7 \%$ & $2.5 \%$ & $0.7 \%$ & $7.3 \%$ \\
\hline Alcoholism & $3.0 \%$ & $5.2 \%$ & $4.4 \%$ & $1.8 \%$ & $1.2 \%$ & $2.3 \%$ \\
\hline Trigeminal neuralgia & $2.7 \%$ & $1.4 \%$ & $3.6 \%$ & $2.5 \%$ & $3.9 \%$ & $2.2 \%$ \\
\hline Postsurgery trauma & $2.4 \%$ & $3.3 \%$ & $1.0 \%$ & $1.6 \%$ & $2.3 \%$ & $4.0 \%$ \\
\hline Trauma/accident & $2.0 \%$ & $1.2 \%$ & $2.6 \%$ & $2.3 \%$ & $2.1 \%$ & $1.9 \%$ \\
\hline Other nerve entrapments/repetitive stress & $1.8 \%$ & $0.4 \%$ & $3.1 \%$ & $1.1 \%$ & $1.6 \%$ & $2.9 \%$ \\
\hline RSD/complex regional syndrome pain & $1.8 \%$ & $1.7 \%$ & $1.7 \%$ & $0.8 \%$ & $2.2 \%$ & $2.5 \%$ \\
\hline Cancer pain (due to treatment) & $1.7 \%$ & $2.5 \%$ & $1.6 \%$ & $2.0 \%$ & $1.9 \%$ & $0.5 \%$ \\
\hline Perioperative neuropathy & $1.7 \%$ & $4.5 \%$ & $1.1 \%$ & $0.8 \%$ & $1.2 \%$ & $0.8 \%$ \\
\hline Phantom limb & $1.4 \%$ & $2.0 \%$ & $1.5 \%$ & $1.4 \%$ & $0.7 \%$ & $1.2 \%$ \\
\hline Vascular damage & $1.3 \%$ & $1.4 \%$ & $2.6 \%$ & $1.1 \%$ & $0.1 \%$ & $1.1 \%$ \\
\hline Cancer tumor infiltration/pressure & $1.1 \%$ & $0.2 \%$ & $0.9 \%$ & $2.9 \%$ & $0.7 \%$ & $0.8 \%$ \\
\hline Lower back pain ${ }^{\mathrm{a}}$ & $24.3 \%$ & $6.6 \%$ & $34.5 \%$ & $30.7 \%$ & $27.0 \%$ & $22.9 \%$ \\
\hline
\end{tabular}

Note: ${ }^{a}$ Based on confirmation by the physician that the patient suffers from back pain and that the site of pain was low back.

Abbreviations: BPI, brief pain inventory; RSD, reflex sympathetic dystrophy.

an analysis of covariance (ANCOVA) model and an ordinary least squares regression model, both of which controlled for patients' country of consultation, age, body mass index (BMI), sex, smoking status, and selected comorbid conditions available in the dataset (anxiety, arthritis, dementia, depression, diabetes, high cholesterol, cancer, hypertension, other cardiovascular disease, respiratory disease, sleep disorder, nausea, and migraine).

Table 4 Main drug classes prescribed for NP ( $>5 \%$ total sample)

\begin{tabular}{lllllll}
\hline Drug class & $\begin{array}{l}\text { Total } \\
(\mathbf{n = 3 , 9 5 6 )}\end{array}$ & $\begin{array}{l}\text { France } \\
(\mathbf{n}=\mathbf{8 0 7})\end{array}$ & $\begin{array}{l}\text { Germany } \\
(\mathbf{n = 8 0 2})\end{array}$ & $\begin{array}{l}\text { Italy } \\
(\mathbf{n}=\mathbf{7 9 2})\end{array}$ & $\begin{array}{l}\text { Spain } \\
(\mathbf{n}=\mathbf{8 2 6})\end{array}$ & $\begin{array}{l}\text { UK } \\
(\mathbf{n}=\mathbf{7 2 9})\end{array}$ \\
\hline Anticonvulsants & $66.2 \%$ & $68.9 \%$ & $68.0 \%$ & $59.5 \%$ & $78.2 \%$ & $55.0 \%$ \\
Opioid analgesics & $25.6 \%$ & $14.9 \%$ & $30.2 \%$ & $31.2 \%$ & $28.3 \%$ & $23.0 \%$ \\
TCADs & $17.4 \%$ & $8.1 \%$ & $13.6 \%$ & $14.8 \%$ & $16.1 \%$ & $36.4 \%$ \\
SNRIs & $13.9 \%$ & $15.1 \%$ & $11.3 \%$ & $15.3 \%$ & $14.3 \%$ & $13.6 \%$ \\
NSAIDs & $13.0 \%$ & $5.5 \%$ & $18.6 \%$ & $13.3 \%$ & $16.6 \%$ & $10.7 \%$ \\
Nonopioid analgesics & $5.9 \%$ & $7.4 \%$ & $3.0 \%$ & $4.0 \%$ & $8.0 \%$ & $7.0 \%$ \\
Anxiolytics & $5.1 \%$ & $10.3 \%$ & $1.7 \%$ & $2.7 \%$ & & $9.3 \%$ \\
\hline
\end{tabular}

Note: ${ }^{a}>90 \%$ paracetamol.

Abbreviations: NP, neuropathic pain; NSAIDs, nonsteroidal anti-inflammatory drugs; SNRIs, serotonin-noradrenalin reuptake inhibitors; TCADs, tricyclic antidepressants. 
Table 5 Physician reported burden data from the disease-specific program

\begin{tabular}{|c|c|c|c|c|c|}
\hline $\begin{array}{l}\text { Physician-reported data } \\
\text { on patient-related burden } \\
\text { of NP }\end{array}$ & $\begin{array}{l}\text { France } \\
(n=807)\end{array}$ & $\begin{array}{l}\text { Germany } \\
(n=802)\end{array}$ & $\begin{array}{l}\text { Italy } \\
(n=792)\end{array}$ & $\begin{array}{l}\text { Spain } \\
(n=826)\end{array}$ & $\begin{array}{l}\text { UK } \\
(n=729)\end{array}$ \\
\hline $\begin{array}{l}\text { Total caregiver support } \\
\text { (\% of the country sample) }\end{array}$ & 107 (I3\%) & 125 (16\%) & $211(27 \%)$ & $|7|$ (2|\%) & I4I (I9\%) \\
\hline $\begin{array}{l}\text { Professional caregiver } \\
\text { (\% of total caregiver) }\end{array}$ & 34 (32\%) & 20 (16\%) & $17(8 \%)$ & $15(9 \%)$ & 29 (2।\%) \\
\hline $\begin{array}{l}\text { Professional caregiver support } \\
\text { (mean hours/week) }\end{array}$ & 10 & 32 & 49 & 31 & 31 \\
\hline
\end{tabular}

Abbreviation: NP, neuropathic pain.

\section{Results}

\section{Demographics}

The DSP database comprised data from 292 specialists and 121 PCPs who completed a total of 3,956 patient records forms (approximately $25 \mathrm{PCP}$ and 60 specialists in each country). Specialists included 83 neurologists, 79 anesthetists, 6 pain clinic physicians, 51 diabetologists, 34 orthopedic surgeons, and 45 rheumatologists (Table 1).

The average age and sex of patients were similar across countries (Table 2). A total of 2,534 also completed the PSC questionnaire, with the highest completion rates being in Germany and the lowest in the Italy. NP diagnoses in each country are detailed in Table 3.

\section{Direct health sector costs}

The average number of consultations was high across the five countries, with a high proportion of specialized care and few nurse visits/consultations (Figure 1).

Across the whole sample, the mean number of prescribed drugs per patient was 1.8 (1.7 in France and Germany, 1.8 in the UK and Italy, and 2.1 in Spain). Table 4 lists the proportion of patients receiving the most commonly prescribed drug classes. Around two-thirds of patients received an anticonvulsant, with use of opioid analgesics second most commonly used by $\sim 25 \%$ of the total sample.
Only a small subsample of the population had received surgery for the management of the disease. In total, 311 surgical procedures were undertaken, ranging from 43 in Italy to 89 in France. A total of 572 patients had a nonsurgical intervention, ranging from 82 in Italy to 145 in Spain. Peripheral nerve decompression was the most commonly used surgical procedure (about one quarter of all surgical procedures), while steroid injection and nerve blocks were the most commonly used nonsurgical interventions.

\section{Direct nonhealth sector costs}

The proportion of patients receiving caregiver support ranged from $13 \%$ (France) to $27 \%$ (Italy). The calculation of total caregiver costs included professional caregiver costs only, based on the number of hours per week recorded. However, as listed in Table 5, this represents only a proportion of total caregiver support provided.

As indicated earlier, it was not possible to estimate the monetary cost of informal care. Informal care is provided by family, friends, neighbors, or other volunteers and is provided free of any payment. However, as shown in Figure 2, the average number of informal (unpaid) care hours per week received implies a significant burden to informal caregivers. While this care is provided free of charge (most generally by a family member), it should be noted that there are several

\section{Mean hours/week}

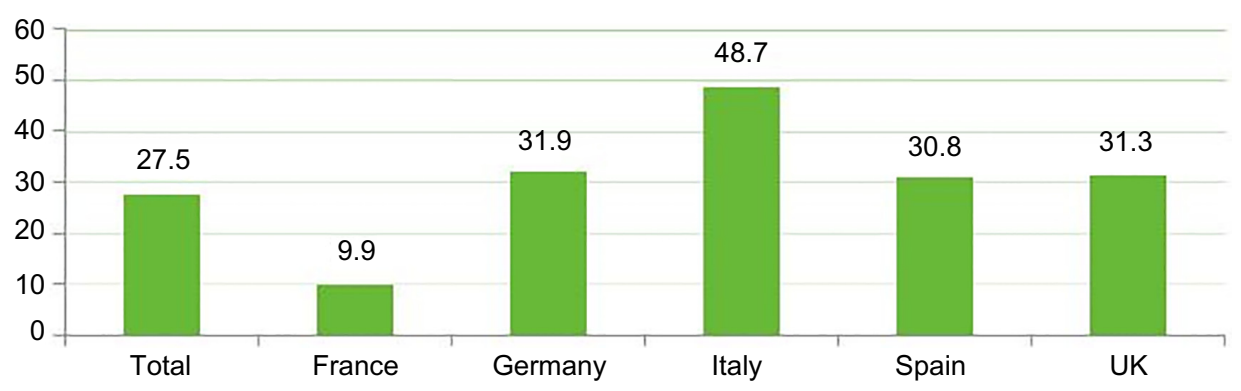

Figure 2 Mean informal caregiver hours provided for patients receiving caregiver support $(n=755)$. 
Table 6 Work loss associated with NP

\begin{tabular}{|c|c|c|c|c|c|}
\hline $\begin{array}{l}\text { Physician-reported data } \\
\text { on patient-related burden } \\
\text { of NP }\end{array}$ & $\begin{array}{l}\text { France } \\
(n=807)\end{array}$ & $\begin{array}{l}\text { Germany } \\
(n=802)\end{array}$ & $\begin{array}{l}\text { Italy } \\
(n=792)\end{array}$ & $\begin{array}{l}\text { Spain } \\
(n=826)\end{array}$ & $\begin{array}{l}\text { UK } \\
(n=729)\end{array}$ \\
\hline $\begin{array}{l}\text { Patients in paid employment } \\
\text { (either full or part time) }\end{array}$ & 277 (34\%) & 269 (34\%) & $278(35 \%)$ & 291 (35\%) & $249(34 \%)$ \\
\hline $\begin{array}{l}\text { Currently on sick leave } \\
\text { (of those full and part time) }\end{array}$ & $58(21 \%)$ & 78 (29\%) & $56(20 \%)$ & $76(26 \%)$ & 40 (16\%) \\
\hline $\begin{array}{l}\text { Duration of current sick } \\
\text { leave to date (weeks) }\end{array}$ & 16.0 & 3.8 & 4.4 & 11.9 & 13.3 \\
\hline Retired due to NP (n) & 11 & 21 & 7 & 20 & 9 \\
\hline $\begin{array}{l}\text { Current mean age of patients } \\
\text { retired due to NP (years) }\end{array}$ & 64.8 & 54.8 & 65.0 & 52.2 & 59.4 \\
\hline
\end{tabular}

Abbreviation: NP, neuropathic pain.

Table 7 Total annual costs per patient per country, 2012

\begin{tabular}{|c|c|c|c|c|c|}
\hline Costs & France & Germany & Italy & Spain & UK \\
\hline \multicolumn{6}{|c|}{ Direct health care costs } \\
\hline Consultations & $€ 282$ & $€ 279$ & $€ 258$ & $€ 477$ & $€ 1,017$ \\
\hline Drugs & $€ I, 697$ & $€ \mathrm{I}, 193$ & $€ \mathrm{I}, \mathrm{I} 70$ & $€ I, 890$ & $€ 1,245$ \\
\hline Surgical procedures & $€ 694$ & $€ 347$ & $€ 338$ & $€ 372$ & $€ 359$ \\
\hline Nonsurgical procedures & $€ 23$ & $€ 30$ & $€ 42$ & $€ 269$ & $€ 97$ \\
\hline Alternative therapies & $€ 126$ & $€ 509$ & $€|3|$ & $€ 123$ & $€ 233$ \\
\hline Total & $€ 2,822$ & $€ 2,358$ & $€ 1,939$ & $€ 3,|3|$ & $€ 2,95$ । \\
\hline \multicolumn{6}{|c|}{ Direct nonhealth care costs } \\
\hline Caregiving & $€ 393$ & $€ 856$ & $€ 984$ & $€ 400$ & $€ 1,242$ \\
\hline \multicolumn{6}{|l|}{ Indirect costs } \\
\hline Sick leave & $€ 7,098$ & $€ \mid I, 232$ & $€ 6,382$ & $€ 7,066$ & $€ 5,492$ \\
\hline All costs total & $€|0,3| 3$ & $€ \mid 4,446$ & $€ 9,305$ & $€ 10,597$ & $€ 9,685$ \\
\hline
\end{tabular}

Table 8 Patient-reported burden data from the disease-specific program

\begin{tabular}{llllll}
\hline Patient-reported data & France $(\mathbf{n = 6 0 2})$ & $\begin{array}{l}\text { Germany } \\
(\mathbf{n = 6 9 6 )}\end{array}$ & $\begin{array}{l}\text { Italy } \\
(\mathbf{n = 2 2 5})\end{array}$ & $\begin{array}{l}\text { Spain } \\
(\mathbf{n = 5 7 7})\end{array}$ & $\begin{array}{l}\text { UK } \\
(\mathbf{n}=\mathbf{4 4 5})\end{array}$ \\
\hline $\begin{array}{l}\text { Patients prevented from working } \\
\text { at some point by NP }\end{array}$ & $163(27 \%)$ & $102(15 \%)$ & $23(10 \%)$ & $97(22 \%)$ \\
$\begin{array}{l}\text { Mean time NP prevented work } \\
\text { (months) }\end{array}$ & 20.7 & 6.7 & 0.6 & 4.9 & 10.3 \\
$\begin{array}{l}\text { WPAl overall work impairment score } \\
\text { (mean) }\end{array}$ & 35.7 & 56.1 & 34.4 & 55.2 & 4.3 \\
$\begin{array}{l}\text { BPI interference score } \\
\text { (average) }\end{array}$ & 4.2 & 4.1 & 4.4 & 4.8 & 4.8 \\
$\begin{array}{l}\text { EQ-5D score } \\
\text { (average) }\end{array}$ & 0.58 & 0.74 & 0.58 & 0.59 & 0.57 \\
\hline
\end{tabular}

Abbreviations: BPI, brief pain inventory; NP, neuropathic pain; WPAI, Work Productivity and Activity Impairment Questionnaire; EQ-5D, EuroQol 5-Dimension.

factors that could result in negative externalities for the economy, such as potential lost working hours resulting in reduction of caregiver income (and tax revenue) given up to provide the care, governmental subsidies for the carer in the form of benefits/allowances and tax breaks.

\section{Indirect costs}

Table 6 lists the impact of NP on employment. The employment rate (full or part time) was consistent across countries, at approximately one-third of the sample in each country.
The proportion of patients who were on sick leave at the time of consultation was consistent, at $\sim 20 \%$ of the sample, although the duration of current sick leave varied considerably between countries. The mean current age of patients reporting NP as the cause of early retirement ranged from 52.2 to 65.0 years; however, the low number $(\mathrm{n}=68)$ precludes any further analysis. Although based on a small subsample, the patient-reported data (PSC) confirmed that the work loss and duration of sick leave can be substantial (Italy had lower numbers than the other countries, but this could be due to a 


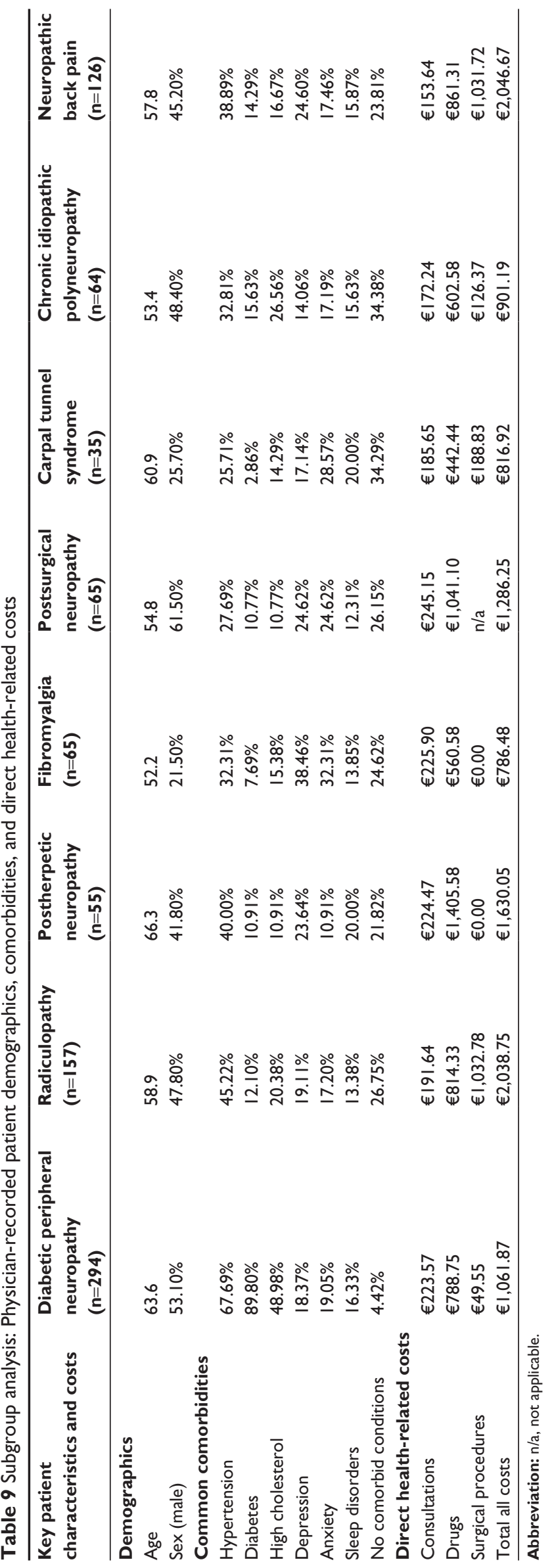

lower rate of response). As can be seen from the mean age of patients who have had to retire early due to their NP pain, significant numbers of patients have been forced to retire before their normal retirement age.

\section{Total costs by country}

Table 7 lists the total per patient costs per country, separated into direct health-related, direct nonhealth-related, and indirect costs. The cross-country variations are driven by the indirect costs calculation, in particular, due to the costs of sick leave, which is the result in part of different annual income rates across countries. Direct health costs and caregiver costs are, however, similar across the countries. Indirect costs constituted 69\% of total costs in France, $78 \%$ in Germany, $69 \%$ in Italy, $67 \%$ in Spain, and $57 \%$ in the UK.

\section{Patient-reported data}

Table 8 presents the patient-reported data from the EQ-5D, BPI, and WPAI. In all countries except Germany, the average EQ-5D score was approximately 0.6 , indicating impaired quality of life comparable score to that of other disabling diseases such as rheumatoid arthritis and chronic obstructive pulmonary disease (Societal Impact of Pain Symposia 2013). ${ }^{37}$ The WPAI score on overall work impairment evaluates the level of impairment, while at work plus the work time missed during the last week. A score of 0 would indicate no impairment, and a score of 100 would indicate that the patient could not undertake any work at all. The results suggest that a significant proportion of the patient's work time in the previous week was affected by NP and that these findings are relatively high compared with other similar diseases. ${ }^{38}$

\section{Subgroup analysis}

Results for the subgroup analysis are listed in Table 9. Only patients with duration of NP longer than 12 months were included. Health-care costs associated with diabetic peripheral neuropathy, radiculopathy, and neuropathic back pain are substantially higher, primarily due to the relatively high proportion of surgical procedures. Table 9 also lists demographics and most common comorbid conditions (those greater than $10 \%$ in the entire sample). Other than for patients with diabetic peripheral neuropathy, the levels of comorbid conditions were similar across the groups, with between one in three and one in five having no other conditions. Because of small sample sizes, this analysis was not broken down by country. It should be noted that these costs appear lower than those observed in the country-by-country analysis. The 
Table 10 ANCOVA model results

\begin{tabular}{|c|c|c|c|c|c|}
\hline Source & Partial SS & $d f$ & MS & $F$ & Prob $>F$ \\
\hline Model & $993,500,000$ & 30 & $33,116,604$ & 3.33 & $<0.001$ \\
\hline Peripheral diseases & $430,800,000$ & 6 & $71,793,414$ & 7.23 & $<0.001$ \\
\hline Country & $157,100,000$ & 4 & $39,282,741$ & 3.95 & 0.004 \\
\hline Age & 562,149 & I & $562,149.1$ & 0.06 & 0.812 \\
\hline BMI & $5,396,605$ & I & $5,396,605$ & 0.54 & $0.46 \mathrm{I}$ \\
\hline Sex (\% male) & $13,249,726$ & I & $13,249,726$ & 1.33 & 0.249 \\
\hline Smoking (Yes) & $3,024,|7|$ & I & $3,024,171$ & 0.3 & 0.581 \\
\hline AIDS/HIV & $32,310,605$ & I & $32,310,605$ & 3.25 & 0.072 \\
\hline Anxiety & $42,204,389$ & I & $42,204,389$ & 4.25 & 0.040 \\
\hline Arthritis & $4,52 I, 4 I I$ & I & $4,52 I, 4 I I$ & 0.46 & 0.500 \\
\hline Dementia & $|5,058,04|$ & I & $|5,058,04|$ & 1.52 & 0.219 \\
\hline Depression & $107,400,000$ & I & $107,000,000$ & 10.82 & 0.001 \\
\hline Diabetes & $27,285,208$ & I & $27,285,208$ & 2.75 & 0.098 \\
\hline High cholesterol & $15,447,825$ & I & $15,447,825$ & 1.56 & 0.213 \\
\hline Cancer & $16,043,722$ & I & $16,043,722$ & 1.62 & 0.204 \\
\hline Hypertension & $65,|44,52|$ & 1 & $65,|44,52|$ & 6.56 & 0.011 \\
\hline Other cardiovascular conditions & 877,928 & I & $877,927.5$ & 0.09 & 0.766 \\
\hline Respiratory disorder & $4,868,147$ & 1 & $4,868,147$ & 0.49 & 0.484 \\
\hline Sleep disorders & $9,516,742$ & I & $9,516,742$ & 0.96 & 0.328 \\
\hline Nausea & $5,332,158$ & I & $5,332,158$ & 0.54 & 0.464 \\
\hline Migraine & 132,764 & I & 132,764 & 0.01 & 0.908 \\
\hline Panic disorders & $17,597,958$ & I & $17,597,958$ & 1.77 & 0.184 \\
\hline None of these conditions listed & $2,320,969$ & I & $2,320,969$ & 0.23 & 0.629 \\
\hline Residual & $6,7 \mid 4,000,000$ & 676 & $9,932,476$ & & \\
\hline Total & $7,708,000,000$ & 706 & $10,917,637$ & & \\
\hline
\end{tabular}

Notes: Number of obs =707; root=3, I5I.58; R-squared =0. 1289 ; Adj R-squared =0.0902.

Abbreviations: ANCOVA, analysis of covariance; $d f$, degrees of freedom; MS, mean square; SS, sum of squares; Prob, probability; BMI, body mass index; AIDS, acquired immunodeficiency syndrome; HIV, human immunodeficiency virus.

reason for this is that the subgroup analysis relates to patients with only one of the more common conditions associated with NP. However, many patients have more than one cause of NP, and these would be expected to have a higher cost burden. However, these have been excluded from the analysis to allow for a direct comparison of the relative burden associated with each of the underlying conditions.

Differences in burden between different patient subgroups (ie, different peripheral diseases) was tested using an ANCOVA model and an ordinary least squares regression model (listed in Tables 10 and 11, respectively), both of which controlled for patients' country of consultation, age, BMI, sex, smoking status, and selected comorbid conditions available in the dataset (anxiety, arthritis, dementia, depression, diabetes, high cholesterol, cancer, hypertension, other cardiovascular disease, respiratory disease, sleep disorder, nausea, and migraine). The results suggested that there exists a statistically significant association between total cost of patient management and peripheral condition the patient suffers from (nominal $P$-value $<0.0001$ ).

Other statistically significant $(P<0.050$ variables in the ANCOVA model included: country of consultation
( $P=0.0035)$, anxiety $(P=0.0397)$, depression $(P=0.0011)$, and hypertension $(P=0.0107)$.

The more granular regression model compared the total cost of patient management between the selected peripheral conditions and the chosen base case (diabetic neuropathy, the most numerous peripheral disease subgroup).

The results suggest that the total cost of patient management of patients with (PHN/Herpes Zoster) $(P=0.006)$, or postsurgical neuropathy $(P<0.001)$ differed significantly from that of patients with diabetic neuropathy. Both PHN and postsurgical neuropathy were found to be more costly than the base (coef. $=1,599.91$ and coef. $=2,868.102$, respectively). Other statistically significant $(P<0.05)$ variables included: anxiety $(P=0.040)$, depression $(P=0.001)$, and hypertension (0.011).

Subgroup analysis was also undertaken regarding work impairment and quality of life (Table 12). Regarding work impairment, the burden is relatively high across all the conditions with the greatest degree of impairment being observed in neuropathic back pain, postherpetic neuropathy, and postsurgical neuropathy. Owing to the small numbers of patients, the costs associated with the impact on work productivity 
Table I I Ordinary least squares regression model results

\begin{tabular}{|c|c|c|c|c|c|}
\hline Independent variables & Coef & Std err & $t$ & $P>|t|$ & $\begin{array}{l}95 \% \text { confidence } \\
\text { interval }\end{array}$ \\
\hline Diabetic peripheral neuropathy & 0 & (base) & & & \\
\hline Spinal nerve root pain (radiculopathy) & 840.02 & 449.09 & 1.87 & 0.06 & -41.76 to $I, 721.81$ \\
\hline Postherpetic neuralgia/Herpes Zoster & $1,599.9 \mid$ & 585.00 & 2.73 & $<0.01$ & $45 I .27$ to $2,748.55$ \\
\hline Fibromyalgia & $-|34.4|$ & 576.51 & -0.23 & 0.82 & $-1,266.37$ to 997.55 \\
\hline Postsurgical neuropathy & $2,868.10$ & 553.26 & 5.18 & $<0.01$ & I,78I.78 to $3,954.42$ \\
\hline Carpal tunel & 8.20 & 685.20 & 0.01 & 0.99 & $-1,337.19$ to $1,353.58$ \\
\hline Chronic ideopathic polyneuropathy & -28.36 & 550.50 & -0.05 & 0.96 & $-1,109.26$ to $1,052.54$ \\
\hline Country: France & 0 & (base) & & & \\
\hline Germany & $-1,136.75$ & 383.46 & -2.96 & $<0.01$ & $-1,889.66$ to -383.84 \\
\hline Italy & -697.96 & 424.21 & -1.65 & 0.10 & $-1,530.88$ to 134.96 \\
\hline Spain & -789.41 & 402.90 & -1.96 & 0.05 & $-1,580.50$ to 1.69 \\
\hline UK & 132.45 & 417.98 & 0.32 & 0.75 & -688.23 to 953.14 \\
\hline Age & -2.67 & II.22 & -0.24 & 0.81 & -24.69 to 19.36 \\
\hline BMI & 20.09 & 27.25 & 0.74 & 0.46 & -33.42 to 73.59 \\
\hline Sex (\% male) & 291.11 & 252.05 & 1.15 & 0.25 & -203.78 to 786.01 \\
\hline Smoker (yes) & 154.68 & 280.33 & 0.55 & 0.58 & -395.74 to 705.11 \\
\hline AIDS/HIV & $4,559.52$ & $2,527.99$ & 1.8 & 0.07 & -404.14 to $9,523.18$ \\
\hline Anxiety & -718.52 & 348.57 & -2.06 & 0.04 & $-1,402.92$ to -34.11 \\
\hline Arthritis & 279.32 & 413.99 & 0.67 & 0.50 & -533.54 to $\mathrm{I}, 092.17$ \\
\hline Dementia & $-1,291.84$ & $1,049.19$ & -1.23 & 0.22 & $-3,351.90$ to 768.22 \\
\hline Depression & $1,069.03$ & 325.07 & 3.29 & $<0.01$ & 430.77 to $1,707.29$ \\
\hline Diabetes & 682.61 & 411.85 & 1.66 & 0.10 & -126.05 to $1,491.26$ \\
\hline High cholesterol & 380.28 & 304.93 & 1.25 & 0.21 & -218.44 to 979.01 \\
\hline Cancer & $-1,066.86$ & 839.43 & -1.27 & 0.20 & $-2,7 \mid 5.06$ to $58 \mid .34$ \\
\hline Hypertension & -786.85 & 307.24 & -2.56 & 0.01 & $-1,390.11$ to -183.58 \\
\hline Other cardiovascular conditions & -133.28 & 448.29 & -0.3 & 0.77 & $-1,013.49$ to 746.93 \\
\hline Respiratory disorder & 353.25 & 504.58 & 0.7 & 0.48 & -637.48 to $I, 343.98$ \\
\hline Sleep disorders & -361.21 & 369.01 & -0.98 & 0.33 & $-1,085.75$ to 363.34 \\
\hline Nausea & $-1,066.20$ & I,455.18 & -0.73 & 0.46 & $-3,923.42$ to $1,791.02$ \\
\hline Migraine & 76.47 & 661.41 & 0.12 & 0.91 & $-1,222.20$ to $I, 375.14$ \\
\hline Panic disorders & $\mathrm{I}, 345.40$ & $\mathrm{I}, 010.76$ & 1.33 & 0.18 & -639.21 to $3,330.01$ \\
\hline None of these conditions listed & 195.43 & 404.28 & 0.48 & 0.63 & -598.36 to 989.22 \\
\hline Constant & 912.47 & $1,060.83$ & 0.86 & 0.39 & $-1,170.44$ to $2,995.38$ \\
\hline
\end{tabular}

Notes: Number of observations =707; $F(30,676)=3.33$; Prob $>F=0.0000 ; R$-squared=0. 1 289; adjusted $R$-squared=0.0902; root $M S E=3$, I5I.6.

Abbreviations: Coef, Coefficient; Std err, standard error; $\mathrm{Cl}$, confidence interval; BMI, body mass index; AIDS, acquired immunodeficiency syndrome; HIV, human immunodeficiency virus; Prob, probability; MSE, mean-square error.

have not been analyzed. Table 12 also lists significant decrements in quality of life (as measured by EQ-5D), with the burden being greatest in radiculopathy and fibromyalgia.

\section{Discussion}

This study demonstrates that there is a meaningful economic and socioeconomic burden associated with NP. Significant annual per patient costs were observed in each of the participating countries, in terms of costs to the health-care system, but more so in terms of societal costs to the wider economy. This study provides a conservative indication of the wider costs, as there are other burdens not collated within this study, which could be quantified in monetary per patient terms.
These results suggest that there is reasonable opportunity cost for society in terms of lost work and productivity due to NP, through work impairment, sick leave, and the potential costs relating to informal care by friends or family members.

Furthermore, the results suggest that a significant proportion of the overall cost, such as informal caregiving and work impairment (as shown with the WPAI overall work impairment score), remains outside of the direct health-care resource use burden, suggesting that a large proportion of the costs associated with NP are not accounted for and are broadly overlooked within current commissioning frameworks and practices across Europe. This is because health-care commissioners focus on direct health service costs, with little consideration of the wider implications of a condition. This can result in 


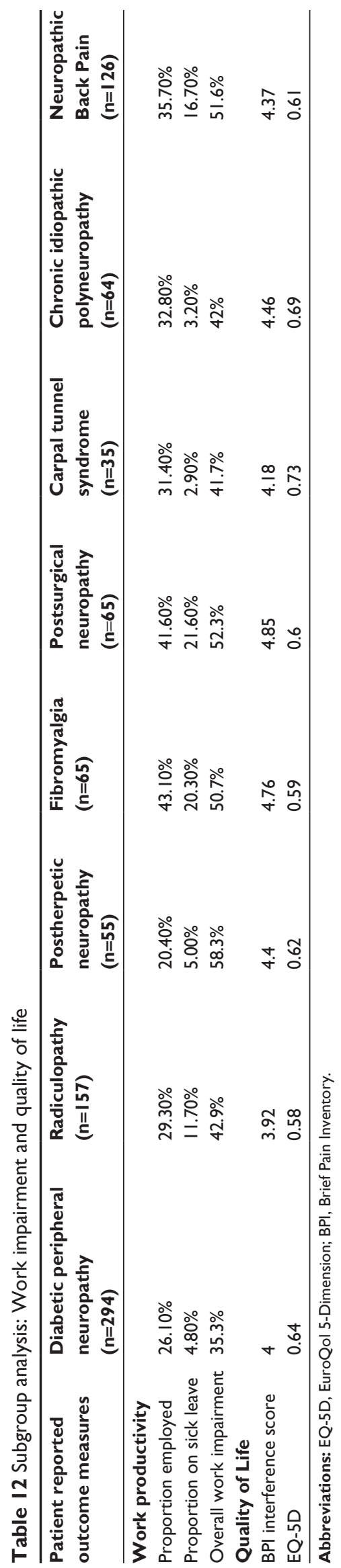

treatment options, which may be cost-effective from a societal perspective not being recognized as such when only direct health-care costs are taken into consideration. It is important to note that some aspects of the burden of illness analysis were described but not translated into monetary terms, suggesting these findings maybe be relatively conservative. This was because the productivity loss/life impact associated with informal caregiving was not collected.

For a small number of patients, NP was stated as the cause of retirement. Although it is clear that a proportion of patients would have retired prior to the standard retirement age (between 60 and 65 depending on country), costs associated with early retirement were not included in the analysis. In addition to the small subsample size ( $\mathrm{n}=68$ ), calculation of the burden of early retirement is problematic for two main reasons. First, the age of retirement is not consistent across Europe. Not only do different countries have different retirement ages, within countries there can be structural differences such as private/public sector employment retirement policy, difference between occupations, and the proportion of self-employed in the economy. Secondly, employed workers who retire can be replaced as required (as the EU does not have full employment), so the true cost to society may be overestimated.

The largest subgroup of NP patients related to diabetic peripheral neuropathy $(n=294)$ and the results of the subgroup analysis suggest that highest direct cost $(\$ 2,046)$ was associated with patients with neuropathic back pain. However, the greatest drug costs were associated with patients with postherpetic neuropathy.

It is important to note that there were differences in age and sex between patients with different causal factors (Table 9). Levels of comorbidity were similar between the patient subgroups however - with the exception of the patients with diabetic peripheral neuropathy where the proportion of patients with diabetes and related complications was clearly much higher. We also observed that the impact on work and quality of life was also significant in each of the conditions assessed.

The ANCOVA model results suggested that there exists a statistically significant association between total cost of patient management and peripheral condition the patient suffers from (nominal $P$-value $<0.0001$ ).

The ordinary least squares model results suggest that the total cost of patient management of patients with (PHN/ Herpes Zoster) $(P=0.006)$, or postsurgical neuropathy $(P<0.001)$ differed significantly from that of patients with diabetic neuropathy.

Our findings support those from research in other regions. For instance, Mehra et $\mathrm{al}^{20}$ conducted an analysis of US 
Claims Data from 2006 to 2008 and reported direct costs of chronic lower back pain in the US of US\$1,007 increasing to US\$2,577 with a neuropathic component.

The literature shows that there is great discrepancy between prevalence estimations in Europe and actual number of diagnoses and/or treated patients with NP; this suggests a "deviated" burden. While it is probable that many nondiagnosed and nonconsulting patients are mild NP sufferers, these patients would likely still have costs associated with their NP which are currently not accounted for.

This study has some limitations. While the data collection methods are homogeneous throughout the five countries and the cost collection remained as homogeneous as possible, there are country-specific differences in terms of clinical management of the disease as care pathways can vary regionally within countries as well as among them, along with differences in the health-care systems (eg, different reimbursement status and access of the drugs and other health technologies, different access schemes to the health systems, and different prescription charges schemes, etc). Consequently, these factors, as well as the differences in unitary costs, make comparison of the different burden of NP in each geographical context challenging. In addition, generic drug costs provide a conservative assumption in the calculation of overall costs that could underestimate the total costs drug.

The data collection did not include any formal diagnostic procedures as part of the inclusion criteria; physicians were briefed to recruit the next ten patients that they were treating for NP. In this context, they included some patients with fibromyalgia as a suggested cause of the NP. We do acknowledge that fibromyalgia may be questioned as a NP syndrome, but our patient sample consists of a real-world sample who are actively being treated for NP in the opinion of the physician regardless of cause. It should be noted that while the survey methodology provides a convenience sample in that the recruitment requires the inclusion of the next $8-10$ patients, the DSP can be considered representative of the consulting population of patients as the requirement of physicians to provide data relating to consecutive consulting patients offers an approximation to a random sample. However, it is acknowledged that the DSP sample may include more recently diagnosed patients, due to the propensity for such patients to visit a physician more frequently. ${ }^{39}$

The data used in these analyses have provided a holistic insight into the qualitative and financial burden within this sample, as the sampling methodology has enabled observation of both the direct and indirect impact associated with individual patients. The results of this real-world survey and analyses highlight the considerable levels of burden associated with NP patients, and the implications for society as a whole, which is often more costly. It has been shown that to consider only healthcare resources greatly underestimates the real burden of NP.

A potential area for future analysis of the data sample is to investigate the relative burden attributed to NP and estimate the incremental burden associated with pain from differing etiologies.

There is evidence of wider cost in terms of lost work productivity and caregiver burden, whether through formal or informal care. However, within current commissioning practices and care pathway structures, there is an apparent lack of refinement regarding how pain is dealt with when the patient initially reports pain. The costs shown suggest a major burden to the whole economy arising from a common symptom (NP) across many indications, a cost that is unlikely to be effectively reduced until overall standard of care is improved and patient pain is rigorously treated upon initial presentation, particularly in lower back pain patients. ${ }^{40}$

\section{Acknowledgments}

Editorial support for the development of this manuscript was provided by Adelphi Values and funded by Grünenthal $\mathrm{GmbH}$. The authors would like to acknowledge Jamie O'Hara and Leonardo Ruis-Casas who worked on the initial analysis for this manuscript.

\section{Disclosure}

Hiltrud Liedgens is an employee of Grünenthal $\mathrm{GmbH}$, and Marko Obradovic was an employee at the time of the study. Tim Holbrook, Jonathan De Courcy, and Rafal Jakubanis are all employees of Adelphi Real World, which provides consultancy services to Grünenthal $\mathrm{GmbH}$.

\section{References}

1. European Commission. Health in the European Union: special eurobarometer 272. 2007. Available from: http://ec.Europa.Eu/health/ph_publication/eb_health_en.Pdf. Accessed January 11, 2016.

2. International Association for the Study of Pain. Iasp taxonomy. Available from: http://www.iasp-pain.org/Taxonomy?navItemNumber=576. Accessed February 10, 2015.

3. Treede R-D, Jensen TS, Campbell J, et al. Neuropathic pain redefinition and a grading system for clinical and research purposes. Neurology. 2008;70(18):1630-1635.

4. Freynhagen R, Baron R, Gockel U, Tolle TR. Paindetect: a new screening questionnaire to identify neuropathic components in patients with back pain. Curr Med Res Opin. 2006;22(10):1911-1920.

5. Freynhagen R, Baron R. The evaluation of neuropathic components in low back pain. Curr Pain Headache Rep. 2009;13(3):185-190.

6. Schmidt CO, Schweikert B, Wenig CM, et al. Modelling the prevalence and cost of back pain with neuropathic components in the general population. Eur J Pain. 2009;13(10):1030-1035. 
7. Berger A, Dukes EM, Oster G. Clinical characteristics and economic costs of patients with painful neuropathic disorders. J Pain. 2004;5(3):143-149.

8. Torrance N, Smith BH, Bennett MI, Lee AJ. The epidemiology of chronic pain of predominantly neuropathic origin. Results from a general population survey. J Pain. 2006;7(4):281-289.

9. Bouhassira D, Lantéri-Minet M, Attal N, Laurent B, Touboul C. Prevalence of chronic pain with neuropathic characteristics in the general population. Pain. 2008;136(3):380-387.

10. Reid KJ, Harker J, Bala MM, et al. Epidemiology of chronic non-cancer pain in europe: Narrative review of prevalence, pain treatments and pain impact. Curr Med Res Opin. 2011;27(2):449-462.

11. O'Connor AB. Neuropathic pain: quality-of-life impact, costs and cost effectiveness of therapy. Pharmacoeconomics. 2009;27(2):95-112.

12. Morlion B. Pharmacotherapy of low back pain: targeting nociceptive and neuropathic pain components. Curr Med Res Opin. 2011;27(1):11-33.

13. Portenoy RK. Opioid therapy for chronic nonmalignant pain: a review of the critical issues. J Pain Symptom Manage. 1996;11(4): 203-217.

14. Kalso E, Edwards JE, Moore RA, McQuay HJ. Opioids in chronic non-cancer pain: systematic review of efficacy and safety (structured abstract). Pain. 2004;112(3):372-380.

15. Hanna M, O’Brien C, Wilson MC. Prolonged-release oxycodone enhances the effects of existing gabapentin therapy in painful diabetic neuropathy patients. Eur J Pain. 2008;12(6):804-813.

16. Attal N, Cruccu G, Baron R, et al. EFNS guidelines on the pharmacological treatment of neuropathic pain: 2010 revision. Eur J Neurol. 2010;17(9):1113-e88.

17. McDermott AM, Toelle TR, Rowbotham DJ, Schaefer CP, Dukes EM. The burden of neuropathic pain: results from a cross-sectional survey. Eur J Pain. 2006;10(2):127-135.

18. Breivik H, Collett B, Ventafridda V, Cohen R, Gallacher D. Survey of chronic pain in Europe: prevalence, impact on daily life, and treatment. Eur J Pain. 2006;10(4):287-333.

19. Smith BH, Torrance N, Bennett MI, Lee AJ. Health and quality of life associated with chronic pain of predominantly neuropathic origin in the community. Clin J Pain. 2007;23(2):143-149.

20. Mehra M, Hill K, Nicholl D, Schadrack J. The burden of chronic low back pain with and without a neuropathic component: a healthcare resource use and cost analysis. J Med Econ. 2011;15(2):245-252.

21. Anderson P, Benford M, Harris N, Karavali M, Piercy J. Realworld physician and patient behaviour across countries: diseasespecific programmes - a means to understand. Curr Med Res Opin. 2008;24(11):3063-3072.

22. Decrees, orders, circulars, General Provisions Ministry of Social Affairs and Health. Available from: https://www.legifrance.gouv. fr/jo_pdf.do? numJO $=0$ \&date $J O=20130228 \&$ num Texte $=19 \&$ pageDebut $=03476 \&$ pageFin $=03753$. Accessed April 2014. French.

23. Kassenärztliche Bundesvereinigung (KBV). Available from: http:// www.kbv.de/media/sp/EBM_Gesamt__Stand_1._Quartal_2015.pdf. Accessed February 10, 2016.

24. AOK - Die Gesundheitskasse. Available from: https://www.aok.de/ bayern/gesundheit/gesundheitsangebote-58700.php?action=detail\&id $=41448 \&$ list=true. Accessed April 2014 .

ClinicoEconomics and Outcomes Research

\section{Publish your work in this journal}

ClinicoEconomics \& Outcomes Research is an international, peerreviewed open-access journal focusing on Health Technology Assessment, Pharmacoeconomics and Outcomes Research in the areas of diagnosis, medical devices, and clinical, surgical and pharmacological intervention. The economic impact of health policy and health systems
25. Lauer-fischer. Winapo/webapo lauertaxe. Prices and products as of 01.08.2013. Available from: http://www2.Lauer-fischer.De/home/. Accessed April 2014.

26. Italian Ministry of Health. Quotidiano online di informazione sanitaria. Available from: www.quotidianosanita.it/allegati/create_pdf. php?all=2201127.pdf. Accessed April 2014.

27. Agenzia Italiana del Farmaco (AIFA). Available from: http://www.agenziafarmaco.gov.it/it/content/liste-di-trasparenza-e-rimborsabilit $\% \mathrm{C} 3 \% \mathrm{~A} 0$. Accessed April 2014.

28. Approval of the national minimum rates of fees for medical and surgical and dental services. http://www.omceoge.org/moduli/ TariffarioMminimoNazionaleD.P.R.17febbraio1992.pdf. Accessed February 10, 2016. Italian.

29. Demartini L, Mearini M, Beccagutti G, Griffi M, Grabbi E. Neurostimolazione spinale: Analisi dei costi di ospedalizzazione in due centri lombardi. Paper presented at: Hta è qualità dei servizi sanitari, Udine, 2011.

30. Ruiz L, Liedgens H, Obradovic M. Cost of illness of neuropathic pain in Spain in 2012 from a societal perspective. Value Health. 2013;16(7):A381.

31. Curtis L. Unit Costs of Health and Social Care 2011. Canterbury, Kent: Personal Social Services Research Unit; 2011.

32. MIMS. Haymarket Media Group. Available from: http://www.mims. co.uk/. Accessed April 2014.

33. Eurostat. Mean Annual Earnings by Sex, Age and Occupation - NACE Rev. 2, b-s Excluding 0. Luxembourg: Eurostat; 2014.

34. McDowell I. Measuring Health: A Guide to Rating Scales and Questionnaires. New York, NY: Oxford University Press; 1996.

35. Hurst N, Kind P, Ruta D, Hunter M, Stubbings A. Measuring healthrelated quality of life in rheumatoid arthritis: validity, responsiveness and reliability of EUROQOL (EQ-5D). Rheumatology (Oxford). 1997;36(5):551-559.

36. Brazier J, Jones N, Kind P. Testing the validity of the euroqol and comparing it with the SF-36 health survey questionnaire. Qual Life Res. 1993;2(3):169-180.

37. Adelphi Real World, Grunenthal. Assessing the burden of neuropathic pain to support the uptake of good practice indicators (gpis): insights from real world data across different diseases. Paper presented at: Societal Impact of Pain Symposia, May 14-15, 2013, Brussels, Belgium.

38. Mitchell BD, Vietri J, Zagar A, Curtis B, Reaney M. Hypoglycaemic events in patients with type 2 diabetes in the United Kingdom: associations with patient-reported outcomes and self-reported hba1c. $B M C$ Endocr Disord. 2013;13(1):59.

39. Babineaux SM, Curtis BH, Holbrook T, Liu L, Colclough H, Piercy J. Evidence for validity of a national physician and patient reported survey in china and UK: the Disease Specific Programme. Paper presented at: 6th Asia-Pacific Meeting of International Society of Pharmacoeconomics and Outcomes Research, 2014, Beijing, China.

40. National Collaborating Centre for Primary Care. Low Back Pain: Early Management of Persistent Non-Specific. NICE Clinical Guidelines, No 88. London, UK: Royal College of General Practitioners; 2009.

organization also constitute important areas of coverage. The manuscript management system is completely online and includes a very quick and fair peer-review system, which is all easy to use. Visit http://www.dovepress.com/testimonials.php to read real quotes from published authors. 